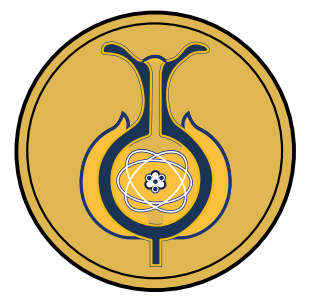

\title{
Knowledge of mathematics teachers in initial training regarding mathematical proofs: Logic-mathematical aspects in the evaluation of arguments
}

Conocimiento de profesores de matemáticas en formación inicial sobre la demostración: Aspectos lógico-matemáticos en la evaluación de argumentos

Conhecimento de professores de matemática em formação inicial sobre a demonstração: Aspectos lógico-matemático na avaliação de argumentos

\section{Christian Alfaro-Carvajal ${ }^{1}$, Pablo Flores-Martínez ${ }^{2}$, Gabriela Valverde-Soto ${ }^{3}$}

Received: Feb/5/2021 • Accepted: Set/16/2021 • Published: Jan/31/2022

\section{Abstract (10)}

The objective of this study is to characterize the knowledge of mathematics teachers in initial training (MTITs) at the Universidad Nacional (Costa Rica) on the logic-syntactic and mathematical aspects involved in proving, when evaluating mathematical arguments. The research is positioned in the interpretive paradigm and has a qualitative approach. It consists of two empirical phases: in the first, a questionnaire regarding logic-syntactic aspects was applied to 25 subjects, during the months of September and October 2018 and; in the second phase, a second questionnaire covering mathematical aspects was applied to 19 subjects, during the months of May and June 2019. For the analysis of the information, knowledge indicators were proposed. Knowledge indicators are understood as phrases to determine evidence of knowledge in the responses of the subjects. It was appreciated that the vast majority of future mathematics teachers show knowledge to discriminate when a mathematical argument corresponds or not to a proof by virtue of the logic and syntactic aspects, and of mathematical elements associated with propositions with the structure of universal implication. In general, subjects displayed greater evidence of knowledge on the logic-syntactic aspects than on the mathematical aspects. Specifically, they evidenced that consideration of a particular case or the proof of the reciprocal proposition does not prove the result; likewise, subjects evidenced knowledge about the direct and indirect proof of the universal implication. In the case of the mathematical aspects considered as hypotheses, axioms, definitions and theorems, it was appreciated that subjects could have different levels of difficulties to understand a proof.

Keywords: mathematics teacher's knowledge; mathematical proof; mathematics teachers in initial training.

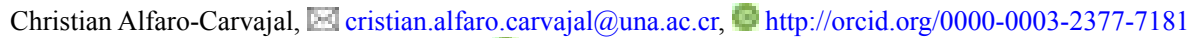

Pablo Flores-Martínez, $\mathbb{3}$ pflores@ugr.es, https://orcid.org/0000-0002-3292-6639

Gabriela Valverde-Soto, $\triangle$ gabriela.valverde@ucr.ac.cr, 9 https://orcid.org/0000-0002-1319-9499

1 Escuela de Matemática, Universidad Nacional, Heredia, Costa Rica.

2 Departamento de Didáctica de la Matemática, Universidad de Granada, Granada, España.

3 Escuela de Formación Docente, Universidad de Costa Rica, San José, Costa Rica. 


\section{Resumen (10)}

El objetivo de este estudio es caracterizar el conocimiento de profesores de matemáticas en formación inicial en la Universidad Nacional de Costa Rica sobre aspectos lógico-sintácticos y matemáticos de la demostración, al evaluar argumentos matemáticos. La investigación se posiciona en el paradigma interpretativo y tiene un enfoque cualitativo. Consta de dos fases empíricas: en la primera, se aplicó un cuestionario sobre los aspectos lógicosintácticos a 25 sujetos, durante los meses de setiembre y octubre de 2018 y, en la segunda, un cuestionario sobre los aspectos matemáticos a 19 sujetos, durante los meses de mayo y junio de 2019. Para el análisis de la información, se propusieron indicadores de conocimientos, entendidos como frases para determinar evidencias de conocimientos en las respuestas de los sujetos. Se apreció que la gran mayoría de los futuros profesores de matemáticas evidencian conocimiento para discriminar cuándo un argumento matemático corresponde 0 no a una demostración en virtud de los aspectos lógicos y sintácticos, y de elementos matemáticos asociados a proposiciones con la estructura de la implicación universal. En general, brindaron mayores evidencias de conocimiento sobre los aspectos lógico-sintácticos que sobre los aspectos matemáticos. Concretamente, evidenciaron que un caso particular o la prueba de la proposición recíproca no demuestra el resultado; asimismo, evidenciaron conocimiento sobre la demostración directa e indirecta de la implicación universal. En el caso de los aspectos matemáticos considerados como las hipótesis, los axiomas, las definiciones y los teoremas, se apreció que podrían tener diferentes niveles de dificultades para comprender una demostración.

Palabras clave: Conocimiento del profesor de matemáticas; demostración matemática; formación inicial de profesores de matemáticas.

\section{Resumo}

Este estudo teve como objetivo caracterizar o conhecimento de professores de matemáticas em formação inicial na Universidade Nacional da Costa Rica sobre aspectos lógico-sintáticos e matemáticos da demonstração ao avaliarargumentos matemáticos. A pesquisa está posicionada no paradigma interpretativo e tem um enfoque qualitativo. Consiste em duas fases empíricas: na primeira foi aplicado um questionário sobre os aspectos lógico-sintáticos a 25 sujeitos, durante os meses de setembro e outubro de 2018 e, na segunda, um questionário sobre os aspectos matemáticos a 19 sujeitos, durante os meses de maio e junho de 2019. Para a análise das informações foram estabelecidos indicadores de conhecimentos, entendidos como frases para determinar evidências de conhecimentos nas respostas dos sujeitos. Constatou-se que a grande maioria dos futuros professores de matemáticas evidencia conhecimento para discriminar quando um argumento matemático corresponde ou não a uma demonstração em função dos aspectos lógicos e sintáticos, e de elementos matemáticos associados às proposiç̧ões com a estrutura da implicação universal. Em geral, foram fornecidos maiores evidências de conhecimento sobre os aspectos lógico-sintáticos do que sobre os aspectos matemáticos. Concretamente, evidenciaram que um caso particular ou a prova da proposição recíproca não demonstra o resultado; da mesma forma, evidenciaram conhecimento sobre a demonstração direta e indireta da implicação universal. No caso dos aspectos matemáticos considerados como as hipóteses, os axiomas, as definições e os teoremas, percebe-se que poderiam ter diferentes níveis de dificuldades para compreender uma demonstração.

Palavras-chave: Conhecimento do professor de matemática; demonstração matemática; formação inicial de professores de matemáticas. 


\section{Introduction}

Proofs are relevant in mathematics and school mathematics. In mathematics, the discovery and prove of new theorems is at the highest level of research, yet there is no generalized definition accepted within the mathematical community. In general, there are two main conceptualizations, one approaching the realm of logic that considers proofs as a sequence of mathematical propositions and the other close to the practice of mathematicians, where semantic and informal aspects have more relevance, thereby considereing proofs more as arguments to convince experts of the validity of a theorem by emphasizing on the explanation of veracity (Cabassut et al., 2012; Hanna and De Villiers, 2012; Tall et al., 2012).

In school mathematics there exists also the debate between the logic-syntactic and semantic aspects of proofs. In some countries, mathematical proving appears in the curriculum as explicit teaching content, while in others as a process standard that must be addressed in the different topics. There is international consensus on its importance in the training of students at all educational levels, because it favors the understanding of mathematics and the processes to develop, establish and communicate mathematical knowledge. In particular, it is advocated to propose tasks to students in which exploration, validation and interpretation generate the need for comprehension, in addition, it is considered important that they confront unexpected results, presenting ambiguities and contradictions to provoke in them the urgency for mathematical proving (Cabassut et al., 2012; Durand-Guerrier et al., 2012a; Mariotti, 2006; NCTM, 2003; Stylianides, 2007; Stylianides et al., 2017; Zaslavsky et al., 2012).
In the case of secondary education in Costa Rica, the mathematics curriculum contemplates the process of "reasoning and argumentation" in students. Mathematical proving is considered as a formal phase of argumentation and plays a relevant role in the formulation of conjectures (Ministerio de Educación Pública, 2012).

To address mathematical proving in the secondary education curriculum, as content or as a process, this topic matter must be part of the knowledge required by mathematics teachers for their teacher performance. In addition to apprehending the contents and their relationships, teachers must know how mathematical knowledge and the syntactic rules of the discipline are produced (Flores-Medrano et al., 2016). In the case of mathematical proofs, teachers must possess specific knowledge that includes knowing about their nature, about their logic and syntactic aspects and; about mathematical aspects, as well as being aware of the role that mathematical proving plays in the discipline of mathematics. Furthermore, teachers must hold specific pedagogical knowledge for the teaching of proving, that is, knowledge of all the elements that enable this topic matter to be tough in school mathematics (Buchbinder and McCrone, 2018; Cabassut et al., 2012; Durand-Guerrier et al., 2012b; Knuth, 2002; Lin et al., 2012; Lo and McCrory, 2009; Pietropaolo and Campos, 2009; Tabach et al., 2009).

Nonetheless, in some investigations it has been detected that mathematics teachers exhibit complex and different conceptions about proofs (Montoro, 2007). All studies point to the importance of mathematical proofs in mathematics (Ayalon and Even, 2008; Ramos et al., 2015; Viseu et al., 2017), however, there are different points of view regarding their role in school mathematics 
(Crespo and Ponteville, 2005; Ramos et al., 2015). Likewise, some teachers show a reduced vision on the nature of proofs, exhibit deficiencies in the involved mathematical knowledge (Martínez-Recio, 1999; Knuth, 2002; Vicario and Carrillo, 2005), present empirical arguments as if they were proofs (Flores, 2007; Stylianides and Stylianides, 2009) and base their conviction on external entities rather than their own knowledge (Lin et al., 2012).

Along this line, the objective of the present study is to characterize the knowledge of mathematics teachers in initial training (i.e., MTITs), belonging to the undergraduate program Bachillerato y Licenciatura en la Enseñanza de la Matemática (translated as Bachelor and Licentiate Program in Mathematics Teaching) at the Universidad Nacional (UNA) in Costa Rica, on the mathematical practice of proving. Since mathematical proving knowledge can encompass several components, and the research subjects (i.e., participants, MTITs) are at a final stage in their formative program and, therefore, have little professional experience, this research was limited to "mathematical knowledge", specifically, to knowledge on the logic-syntactic and mathematical aspects involved in the evaluation of mathematical arguments.

The present work is contextualized within the line of research on the training of mathematics teachers and is part of the greater research group "FQM 193. Didactics of Mathematics. Numerical Thinking". The work specifically deals with the topic of mathematical knowledge evidenced by MTITs regarding the mathematical practice of proving from the perspective of teacher performance. Its contribution to this area of research lays in providing inputs that can favor the manner in which mathematical proving is approached in the curricular plan of MTITs at the Universidad Nacional in Costa Rica, and similar initial training plans elsewhere, and realizes a theoretical contribution in the construction of gauging components for the study of the state of knowledge of MTITs regarding mathematical proving, particularly through the use of knowledge indicators for logic-syntactic and mathematical aspects.

\section{Theoretical framework}

The study of the professional knowledge evidenced by mathematics teachers is a focus of interest in research in Mathematics Education. Notable works conducted in the eighties are those of Elbaz (1983) and Shulman (1986), the investigations carried out by the International Group for the Psychology of Mathematics Education (IGPME) (Ponte and Chapman, 2006), and the theoretical perspectives on knowledge, as well as beliefs within teaching and teacher performance of mathematics teachers described in the The Handbook of Mathematics Teacher Education (Sullivan \& Wood, 2008).

To study the specialized knowledge on mathematical proving possesed by mathematics teachers, interest centers then around knowledge on mathematical tasks, that is to say, the way in which knowledge is produced in mathematics (Carrillo et al., 2018; Flores-Medrano et al., 2016). Thus, to carry out the present research, it was considered pertinent to have a theoretical model of the knowledge evidenced by mathematics teachers that would include mathematical proving within a category of knowledge. The Mathematics Teacher's Specialized Knowledge (MTSK) model considers this type of knowledge as part of mathematical knowledge owned by mathematics teachers 
and assigns a subdomain within it, denominated Knowledge of Practices in Mathematics (KPM) (Carrillo et al., 2018).

The model takes an analytical approach with the purpose of obtaining information about the teacher's knowledge, particularly about the elements that compose it and their interactions. For this, two domains are considered: (1) mathematical knowledge and (2) pedagogical content knowledge (Carrillo et al., 2018). The object of practice in the context of the present research is mathematics itself and, therefore, the interest is focused on its operation and not on the process of its teaching. Mathematical practice is understood in the sense indicated by Carrillo et al. (2018) as any mathematical activity carried out in a systematic way, that is fundamental in the creation of mathematical knowledge and that posseses a logic basis that allows the derivation of rules.

According to Carrillo et al. (2018), "Knowledge of Practices in Mathematics (KPM)" can be general or topic specific. General "mathematical practice" refers to the teacher's knowledge on how mathematics is developed in a generic manner and independent of particular topics. "Specific mathematical practice" is a particular case of ), "Knowledge of Practices in Mathematics (KPM)" and is associated with the particularities of the mathematical topic in question. In this research, it is considered that knowledge of the logic and syntactic aspects of mathematical proving is attended by general mathematical practice since, as indicated by Carrillo et al. (2018), it encompasses the knowledge of the meaning of the necessary and sufficient conditions, the type of proof to guarantee the veracity of a mathematical statement, the various argumentative practices, among others. Likewise, knowledge about the mathematical aspects of proving is considered by specific mathematical practice, since not only is general logic-syntactic knowledge required, but it also considers the mathematics involved in the propositions and their proofs.

To characterize the knowledge on logic and syntactic aspects of mathematical proving evidenced by MTITs at the Universidad Nacional in Costa Rica, three elements of logic validity have been considered, which were specified based on the conceptual analysis of mathematical proofs (Alfaro, Flores and Valverde, 2019): (1) type of proof, (2) type of quantifier and (3) the type of logic connective. Regarding the mathematical aspects of proving, it must be considered that mathematical theories are hypothetical and are made up of propositions of the "if - then" form which means that mathematical proving requires rigor. The axioms, hypotheses, definitions and theorems involved must be understood and applied in their exact meanings (Cabassut et al., 2012). In a formal theory or mathematical system, three fundamental elements are distinguished: (1) axioms, (2) definitions and (3) theorems (Cabassut et al., 2012; Garrido, 1991; Patterson, 1950; Roberts,2010).

\section{Methodology}

The present work is positioned in the interpretive paradigm and has a qualitative approach because the object of interest is the interpretation of the meanings that the subjects (i.e., participants, MTITs) attribute to their actions (Bryman, 2012; Cohen, Manion and Morrison, 2007; Rodríguez, 2003; Sandín, 2003). It consists of two empirical phases aimed at characterizing the knowledge of MTITs at the Universidad Nacional, regarding: (1) the logic and 
syntactic aspects of mathematical proving, which correspond to the "logic validity" of mathematical proofs and (2) the mathematical aspects of proving, which correlate to the "mathematical validity" of proofs.

The undergraduate program in Mathematics Teaching at the Universidad Nacional is a joint program, the School of Mathematics offers the mathematical component and the Division of Educology provides the pedagogical component. Upon completion of a 4-year academic curriculum, students obtain the degree of Bachelor extendable to an optional Licentiate degree upon achievement of three additional semesters and the preparation of a final graduation project. In phase 1 of the study, 25 MTIT subjects participated, of which 18 were enrolled in the fourth and final year of the bachelor program and were thus denominated Bachelor Group (BG); 7 subjects were enrolled in the optional licentiate program and were identified as the Licentiate Group (LG). Both groups constituted the entire population of enrolled and active students at the corresponding academic levels during the second semester of 2018. In phase 2 of the study, 19 MTIT subjects participated, 12 were enrolled in the fourth year (BG) and 7 in the fifth year (LG), similarly, both groups corresponded to the entire enrolled and active student body at the corresponding academic levels during the first semester of 2019. Of the 12 subjects enrolled in the fourth year, 11 participated in phase 1 . All 7 subjects enrolled in the fifth year had previously participated participated in phase 1 of the study. Subjects were coded using the letter "S" to indicate that they were undergraduate students; "B" bachelor or "L" licentiate; letters " $\mathrm{M}$ " and "W" designate man and woman, respectively; bachelor subjects were numbered 01 to 19 and licentiate from 01 to 07 .
All research subjects have approved the academic courses contempleted in the program's curriculum thus demonstrating proficiency in mathematical propositions.

\section{Information gathering}

For collecting information in phases 1 and 2, two questionnaires were elaborated. Questionnaire 1 denominated "logic validity in the evaluation of mathematical arguments" was applied in September and October 2018 and questionnaire 2, "mathematical validity in the evaluation of mathematical arguments", was applied in the months of May and June 2019, both with an approximate duration of one hour. In each case, subjects completed the questionaires individually during the schedules assigned to the enrolled courses. Prior to their application, questionnaires were reviewed by three Mathematics Education specialists who were chosen for their training in mathematics and mathematics didactics, in addition to their extensive knowledge of the educational context of the research subjects (MTITs).

The creation of both questionnaires contemplated elements from the theoretical framework of logic and mathematical validity knowledge involved in mathematical proving. In the case of questionnaire 1 , research subjects had to evaluate the way to proceed in proving proposition $P$ : Any real number satisfies that, if it is positive, then the sum of it and its multiplicative inverse is greater than or equal to two (Winicki-Landman, 1998). This proposition was used by Knuth (2002) in his research with 16 mathematics teachers where he presented them with an argument that proved the reciprocal predicate. In questionnaire 1 , in addition to the argument on the reciprocal, three 
additional arguments were included, one considers a particular case and the other two present a direct proof and proof by reduction to absurdity. In this way, the questionnaire consists of four tasks. In addition, the veracity of said proposition was indicated. Table 1 provides each of the mathematical arguments presented with the tasks.

Questionnaire 2 consists of four tasks. In each of them, a mathematical proposition and a mathematical argument are presented to guarantee their validity. The first three arguments have errors with respect to mathematical aspects, specifically, in the first task, an inappropriate use is made of the "hypothesis" of the mathematical proposition; in the second, the improper use of an "axiom" and in the third, the improper use of "definitions". In the event that subjects (i.e., MTITs) would detect errors, they were asked to indicate what modifications they would apply to the argument to convert it to a mathematical proof. Table 2 provides each of the mathematical propositions and mathematical arguments presented in the tasks.

Table 1. Mathematical arguments involved in the tasks of questionnaire 1

Task Mathematical argument

Task 1:

Proof by a

particular case

Task 2:

Proof of reciprocal

Task 3:

Direct proof of the universal implication
Consider the real number $(2-\sqrt{3})$. It is clear that $(2-\sqrt{3})>0$. Additionally, $(2-\sqrt{3})+$ $\frac{1}{(2-\sqrt{3})}=\frac{(2-\sqrt{3})^{2}+1}{2-\sqrt{3}}=\frac{4-4 \sqrt{3}+3+1}{2-\sqrt{3}}=\frac{4(2-\sqrt{3})}{2-\sqrt{3}}=4$.

Since it is true that $4 \geq 2$, hen the validity of the proposition $\boldsymbol{P}$ is guaranteed.

Consider any real number $x$. Suppose true that the sum of this number and its multi-

plicative inverse is greater than or equal to two, that is, $\left(x+\frac{1}{x}\right) \geq 2$. Then, $\frac{x^{2}+1}{x} \geq 2$ and thus $\frac{x^{2}+1}{x}-2 \geq 0$. Performing a substraction on the left side of the inequality results in $\frac{x^{2}+1-2 x}{x} \geq 0$ which on rearranging and factoring the fraction's numerator, one arrives at $\frac{(x-1)^{2}}{x} \geq 0$. Because $\frac{(x-1)^{2}}{x} \geq 0$ is true and, additionally, $(x-1)^{2} \geq 0$ is also true, it is concluded that $x>0$. Consequently, the proposition $\boldsymbol{P}$ is true.

Consider any real number $x$. Suppose true that the number is positive, that is, $x>0$. It must be guaranteed that the sum of this number and its multiplicative inverse is greater than or equal to two, namely $\left(x+\frac{1}{x}\right) \geq 2$. Indeed, $x+\frac{1}{x}-2=\frac{x^{2}+1}{x}-2=\frac{x^{2}+1-2 x}{x}=\frac{x^{2}-2 x+1}{x}=\frac{(x-1)^{2}}{x}$. Since $(x-1)^{2} \geq 0$ is true and, additionally, $x>0$ then it is true that $\frac{(x-1)^{2}}{x} \geq 0$. Therefore, it is true that $\left(x+\frac{1}{x}-2\right) \geq 0$ and thus, necessarily, $\left(x+\frac{1}{x}\right) \geq 2$ olds true, as it was intended to demonstrate. Consequently, proposition $\boldsymbol{P}$ is true.

Task 4: $\quad$ Suppose that there exists a real number $x$ that satisfies being positive and that the Proof of the universal implication by reduction to absurdity sum of it and its multiplicative inverse is less than two, that is, $x>0$ and $\left(x+\frac{1}{x}\right)<2$.

Thus $\left(x+\frac{1}{x}-2\right)<0$. On the other hand, $x+\frac{1}{x}-2=\frac{x^{2}+1}{x}-2=\frac{x^{2}+1-2 x}{x}=\frac{x^{2}-2 x+1}{x}=\frac{(x-1)^{2}}{x}$ . Consequently, $\frac{(x-1)^{2}}{x}<0$ and since $x>0$ it must necessarily be true that $(x-1)^{2}<0$. Since it is true that $(x-1)^{2} \geq 0$ then the proposition $\left.(x-1)^{2}<0 \wedge(x-1)^{2} \geq 0\right)$ is true, however, it is certain that it is false. Consequently, proposition $\boldsymbol{P}$ is true.

Note: Own source from the present investigation. 
Table 2. Mathematical propositions and arguments involved in the tasks of questionnaire 2

\section{Task and mathematical Mathematical argument proposition}

\section{Task 1: partial use of the non-negative discriminant hypothesis}

P1: If $a, b, c \in \mathbb{R}$ are such that $\mathrm{a} \neq 0$ and $\left(b^{2}-4 a c\right) \geq 0$, then $\left(a x^{2}+b x+c=0\right)$.

Task 2: improper use of the axiom of existence of the multiplicative inverse P2: If $m, n \in \mathbb{Z}$ are such that $m$ divides $n$ and vice versa, then $|m|=|n|$.

Task 3: improper use of the definitions of odd and even integer

If $m, n \in \mathbb{Z}$ are such that $m$ and $n$ are odd numbers, then $m+n$ is an even number.

Task 4: proper use of hypotheses, axioms, definitions and theorems in the proof of the theorem of the sum of the measures of the interior angles of a triangle in Euclidean geometry In any triangle in Euclidean geometry the sum of the measures of the interior angles of a triangle is 180 degrees. That is, given any triangle $\triangle A B C$, it is true that $m \angle A+m \angle B+m \angle C=180^{\circ}$
Suppose we have $a, b, c \in \mathbb{R}$ such that $\mathrm{a} \neq 0 \mathrm{y}\left(b^{2}-4 a c\right) \geq 0$. It must be demonstrated that $\exists \mathrm{x} \in \mathrm{R}\left(a x^{2}+b x+c=0\right)$. Consider the real number $x=\frac{-b}{2 a}$. Then $a x^{2}+b x+c=a\left(\frac{-b}{2 a}\right)^{2}+b\left(\frac{-b}{2 a}\right)+c=$ $\frac{b^{2}}{4 a}-\frac{b^{2}}{2 a}+c=\frac{b^{2}-2 b^{2}+4 a c}{4 a}=\frac{-\left(b^{2}-4 a c\right)}{4 a}$. With $\left(b^{2}-4 a c\right) \geq 0$ as hypothesis, it can be particularly assumed that $\left(b^{2}-4 a c\right)=0$ and thus $a x^{2}+b x+c=\frac{-\left(b^{2}-4 a c\right)}{4 a}=\frac{-0}{4 a}=0$. Hence, the real number $x=\frac{-b}{2 a}$ sastisfies existence.

Suppose that $m, n \in \mathbb{Z}$ such that $m$ divides $n$ and vice versa. It must be shown that $|m|=|n|$. Indeed, since $m$ divides $n$ and vice versa, then, there are two integers $p, q$ such that (1) $m=n \cdot p$ and (2) $n=m \cdot q$. By substituting (1) in (2) it follows that $n=(n \cdot p) \cdot q$, and thus by multiplying both sides of the equality by $n^{-1}$ we have that $p \cdot q=1$. Since $p$ and $q$ are integers, it follows that $p=$ $q=1$ or $p=q=-1$. If $p=q=1$, then substituting in (1) we have $m=n$ and, consequently, $|m|=|n|$. In either case, it is guaranteed that $|m|=|n|$.

Suppose we have $m, n \in \mathbb{Z}$ such that $m$ y $n$ s are odd numbers. It must be shown that $m+n$ is an even number. Indeed, since $m$ y $n$ are odd numbers, then, according to the definition of odd number it follows that there exists two integers $p, q$ such that (1) $2 m+1=p$ and (2) $2 n+1=q$. Then $(2 m+1)+(2 n$ $+1)=p+q$ and in this manner it follows that $2 m+2 n 2=p+q$, hat is, $2(m+$ $n)=p+q-2$. Let $j=p+q-2$ and since $p, q, 2 \in \mathbb{Z}$ then $j \in \mathbb{Z}$. Thus $2(m+n)$ $=j$, where $j \in \mathbb{Z}$ which, according to the definition of even number, guarantees that $m+n$ is an even number.

Suppose we have any triangle $\triangle A B C$ in Euclidean geometry. It must be shown that the sum of the measures of its interior angles is 180 degrees, that is, $m$ $\angle A+m \angle B+m \angle C=180^{\circ}$. Indeed, since point B does not belong to line $\overleftrightarrow{A C}$ then, by virtue of the parallel postulate, a unique line $L$ exists that contains $B$ and is parallel to line $\overleftrightarrow{A C}$. Consider the following figure illustrating the above description:

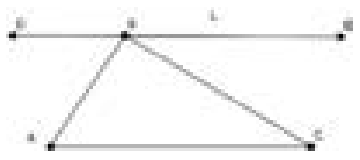

Let $D$ y $E$ be two points on line $L$ such that $D-B-E$ and the points $A$ and $D$ are on the same side of line $\overleftrightarrow{B C}$. Since point $A$ is contained within angle $\angle$ $D B C$, it follows that $m \angle D B C=m \angle D B A+m \angle A B C$. Also, $m \angle D B C+m \angle C B E$ $=180^{\circ}$, since both angles form a linear pair. In this way we have that $m \angle D B A+$ $m \angle A B C m \angle C B E=180^{\circ}(*)$. On the other hand, $m \angle D B A=m \angle B A C$ since the angles are alternate interior angles between parallels. Furthermore, $m \angle D B A$ $=m \angle B A C$ because they are also alternate interior angles between parallels. Substituting in (*) we obtain that $m \angle B A C+m \angle A B C+m \angle B A C=180^{\circ}$ which is equivalent to $m \angle \mathrm{A}+m \angle B+m \angle C=180^{\circ}$.

Note: Own source from the present investigation. 


\section{Methodological aspects of informa- tion analysis}

Information collected from both questionnaires was examined by content analysis which is a scientific research technique for making replicable and valid inferences from texts (or other meaningful matter) to the contexts of their use (Cohen, Manion, y Morrison, 2007; Krippendorff, 2004).

To analyze the responses of the subjects of questionnaire 1 , the syntactic structure of the given proposition was considered and for each argument an a priori analysis of the elements of knowledge on the logic validity that could be studied was made. Based on the latter, four categories were considered: (1) proof by a particular case, (2) proof of reciprocal, (3) direct proof of the universal implication, and (4) proof of the universal implication by reduction to absurdity. Based on the study of each of the four arguments, knowledge indicators were generated which are phrases to ascertain evidence of knowledge in the subjects' responses. Such indicators are presented in Table 3.

The responses of each subject were thoroughly reviewed, and coded $\mathbf{1}$ or $\mathbf{0}$ for presence or absense of knowledge indicators, respectively. Additionally, the responses, and a synthesis of them, that could not be classified by such indicators were recorded. The procedure followed for coding subject responses that gave rise to the results is illustrated for Task 1-proof by a particular case. The

Table 3. Knowledge indicators generated for the universal implication of questionnaire 1

\begin{tabular}{ll}
\hline \multicolumn{1}{c}{ Tasks } & Generated Knowledge indicators \\
\hline TASK 1 & Manifests that the argument is not a proof because a particular case is considered.
\end{tabular}

Argument 1: proof by a particular case

TASK 2

Argument 2: proof of reciprocal

TASK 3 Argument 3: direct proof of Manifests that the antecedent $x>0$ must be assumed to be a true proposition. the universal implication

TASK 4

Argument 4: proof of the universal implication by reduction to absurdity
Manifests that the argument is not a proof because the reciprocal of the predicate is considered, that is, the consequent $\left(x+\frac{1}{x}\right) \geq 2$ is assumed to be true and the veracity of the antecedent $x>0$ is guaranteed.

Manifests that an arbitrary element of the universe $\mathbb{R}$ must be considered.

Manifests that it must be guaranteed that the consequent $\left(x+\frac{1}{x}\right) \geq 2$ is a true proposition based on the antecedent $x>0$ and the mathematical theory where both propositions are inserted.

Manifests that the property $x>0 \Rightarrow\left(x+\frac{1}{x}\right) \geq 2$ is satisfied for all the elements of the universe set $\mathbb{R}$ because it had been validated for an arbitrary element. Manifests that the negation of the given proposition must be assumed to be true and that it is equivalent to the proposition $\exists x \in \mathbb{R}\left[x>0 \wedge\left(\frac{x^{2}+1}{x}\right)<2\right]$. Manifests that it must be shown that $\neg \forall x \in \mathbb{R}\left(x>0 \Rightarrow\left(x+\frac{1}{x}\right) \geq 2\right) \Rightarrow F_{0}$ where $F_{0}$ represents any contradictory statement, in this case $F_{0}$ is the contradiction $\left((x-1)^{2}<0 \wedge(x-1)^{2} \geq 0\right)$.

Manifests that once $F_{0}$ is guaranteed then $\neg \forall x \in \mathbb{R}\left(x>0 \Rightarrow\left(x+\frac{1}{x}\right) \geq 2\right)$ must be false and, consequently, $\forall x \in \mathbb{R}\left(x>0 \Rightarrow\left(x+\frac{1}{x}\right) \geq 2\right)$ must be true.

Note: Own source from the present investigation. 
responses of subject SBW12 for tasks 1 and 2 are presented.

Based on the analysis of Figure 1, it is certain that the subject evidences in his response the following knowledge indicator defined for task 1 (see table 3): "the argument is not a proof because it is considered a particular case". Thus, such response is coded as $\mathbf{1}$ for this particular indicator.

Based on the analysis of Figure 2, it is certain that the subject evidences in his response the knowledge indicator defined for task 2 (see table 3): "the argument is not a proof because it is considered the reciprocal of the predicate, that is, the consequent $\left.\left(x+\frac{1}{x}\right) \geq 2\right)$ is assumed to be true and the veracity of antecedent $x>0$ is guaranteed", therefore, $\mathbf{1}$ is assigned.

To analyze the responses of the subjects in questionnaire 2, four categories were established based on the elements of mathematical validity raised in the theoretical framework: "(1) partial use of the non-negative discriminant hypothesis"

Translation of task statement and response (justification) provided by the subject

\section{TASK 1}

P: Any neal number satisfies that, if it is positive, then the sum of if and its multiplicative inverse is gneater than or equal to thea.

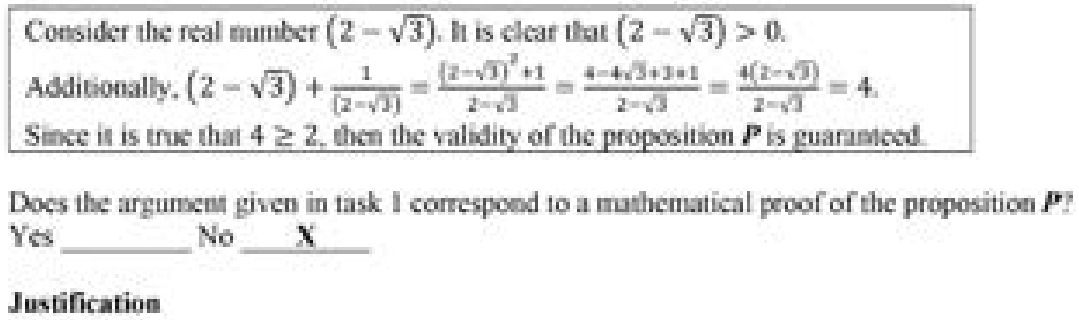

Justification

The proposition P states that for any real number, that is, it is a universal quantifier, the presented argument does not satisfy this, since it is a particular case, the proposition $P$ f fulfills that specific element, however, this does not prove the generality of statement of $f^{\circ}$.

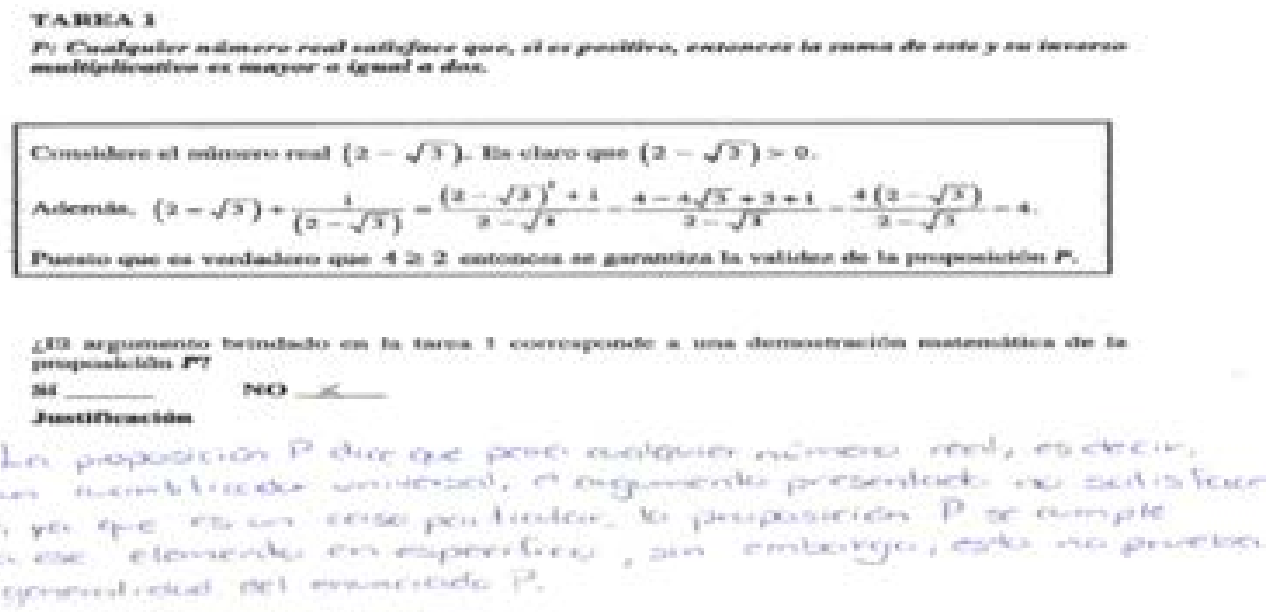

Figure 1. Response of subject SBW12 for task 1 
Translation of task statement and response (justification) provided by the subject

TASK 2

$P$ : Any real aumber satisfies that, if it is pesitive, then the sum of it and its multiplicathe inverse is greater than or equal to twe.

Consider any real number $x$. Suppose true that the sum of this number and its multiplicative imerse is greater than or equal to two, that is, $\left(x+\frac{3}{x}\right) \geq 2$. Then, $\frac{x^{2}+1}{x} \geq 2$ and thus $\frac{x^{3}+t}{x}-2 \geq 0$. Perforning a sebsaractioe on the lef side of the incquality results in $\frac{x^{2}+1-2 x}{x} \geq 0$, which on rearranging and factoring the fraction's numerator, one amives at $\frac{(x-1)^{2}}{x} \geq 0$. Because $\frac{(x-1)^{2}}{x} \geq 0$ is true and, asditiceally, $(x-1)^{2} \geq 0$ is also true, it is concluded that $x>0$. Conseguently, the proposition $P$ is true:

Does the argument given in task 2 cortespond to a mathentatical proof of the proposition $\boldsymbol{P}$ ? Yes No $\mathbf{X}$

\section{Justification}

"The angument presented is sot a valid proof, since the proposition $P$ corresponds to an implisation, nbere the bypothesis is that $x$ is positive, with $x \in \mathbb{R}$ and the thesis is that the sum of $x$ with is multiplicative inverse is greaser than or equal to two. The argument takes as hypothesis stat corresponds wo the thesis and as a thesis what corresponds to the hypoehesis. This is an incorrect way of demensirating an implication".

TABra?

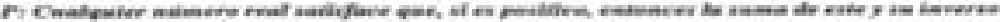

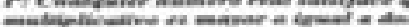
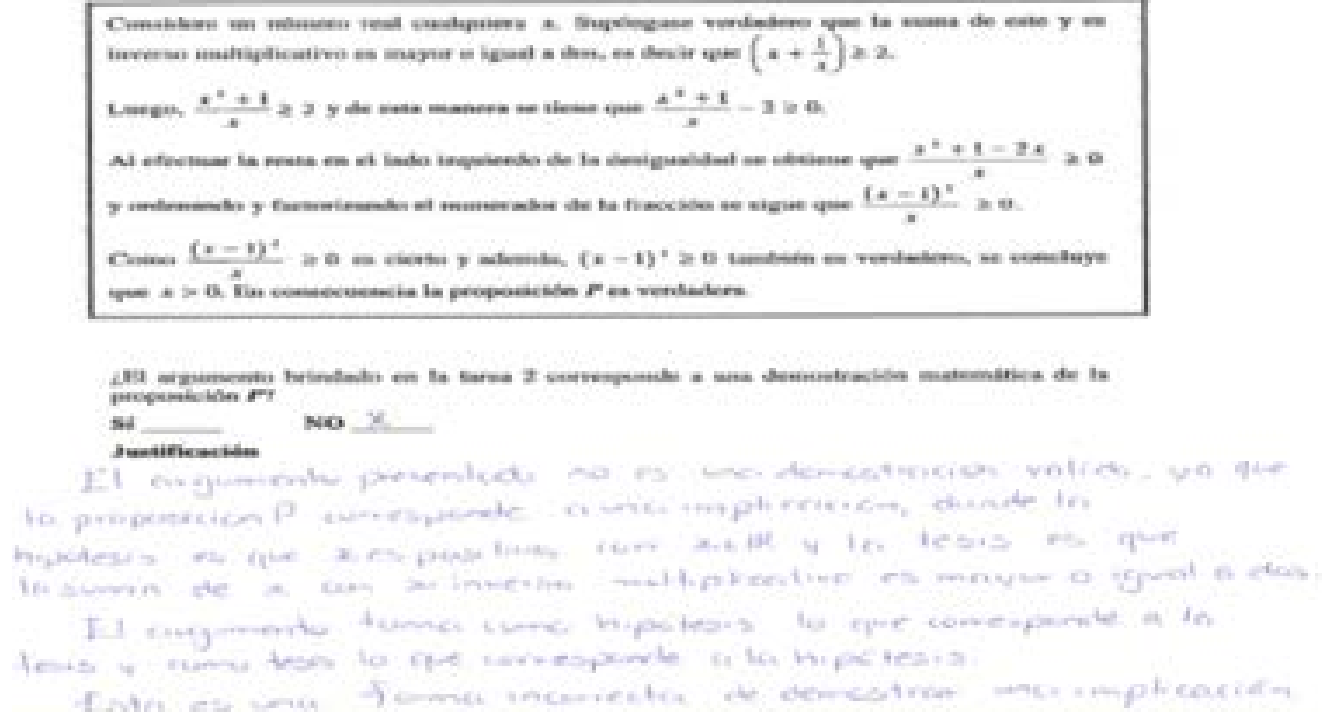

Figure 2. Response of subject SBW12 for task 2

present in task 1, “(2) improper use of the axiom of existence of the multiplicative inverse" present in task 2, "(3) improper use of the definitions of odd and even integer" present in task 3 and "(4) proper use of hypotheses, axioms, definitions and theorems in the proof of the theorem of the sum of the measures of the interior angles of a triangle in Euclidean geometry" present in task 4 .

For each of the tasks, the researchers analyze a priori the mathematical elements that are consider could be taken into account in the evaluation of the arguments involved. This process is illustrated in task 1 , where 
the argument is not a mathematical proof because the non-negative discriminant hypothesis $\left(b^{2}-4 a c\right) \geq 0$ is partially used by assuming that $b^{2}-4 a c=0$. Based on this, a knowledge indicator was proposed for the explanation that the argument is not a mathematical proof, namely: "Manifests that the argument is not a proof because the hypothesis $\left(b^{2}-4 a c\right) \geq 0$ " is partially used". To effectuate the modification of the argument to make it a proof, it was considered that the hypothesis $\left(b^{2}-4 a c\right) \geq 0$ must be used and, based on it, exhibit in the correction at least one of the following real numbers $x=\frac{-b+\sqrt{b^{2}-4 a c}}{2 a}$ o $x=\frac{-b-\sqrt{b^{2}-4 a c}}{2 a}$. Thus, two knowledge indicators were raised: "Manifests that the hypothesis $\left(b^{2}-4 a c\right) \geq 0$ must be considered for correcting the argument, however, it does not exhibit any of the real numbers that satisfy existence" and "Manifests that the hypothesis $\left(b^{2}-4 a c\right) \geq 0$ must be considered in order to exhibit any of the real numbers $x=\frac{-b+\sqrt{b^{2}-4 a c}}{2 a}$ o $x=\frac{-b-\sqrt{b^{2}-4 a c}}{2 a}$ in the argument's correction". Table 4 presents the knowledge indicators associated with the tasks of questionnaire 2.

Table 4. Knowledge indicators developed for the analysis categories of questionnaire 2

\begin{tabular}{|c|c|}
\hline Tasks & Generated Knowledge indicators \\
\hline $\begin{array}{l}\text { TASK } 1 \\
\text { Argument 1: partial } \\
\text { use of the non-negative } \\
\text { discriminant hypothesis }\end{array}$ & $\begin{array}{l}\text { Manifests that the argument is not a proof because the hypothesis } \\
\left(b^{2}-4 a c\right) \geq 0 \text { is partially used. } \\
\text { Manifests that the hypothesis }\left(b^{2}-4 a c\right) \geq 0 \text { must be considered for correcting } \\
\text { the argument, however, it does not exhibit any of the real numbers that satisfy } \\
\text { existence. } \\
\text { Manifests that the hypothesis }\left(b^{2}-4 a c\right) \geq 0 \text { must be considered in order to ex- } \\
\text { hibit any of the real numbers } x=\frac{-b+\sqrt{b^{2}-4 a c}}{2 a} \text { or } x=\frac{-b-\sqrt{b^{2}-4 a c}}{2 a} \text { in the argument's } \\
\text { correction. }\end{array}$ \\
\hline $\begin{array}{l}\text { TASK } 2 \\
\text { Argument 2: improper use } \\
\text { of the axiom of existence of } \\
\text { the multiplicative inverse }\end{array}$ & $\begin{array}{l}\text { Manifests that the argument is not a proof because the multiplicative inverse } \\
\text { axiom is used incorrectly when considering the real number } n^{-1} \text { without guar- } \\
\text { anteeing that } n \neq 0 \text {. } \\
\text { Manifests that two cases must be considered for the correction of the argu- } \\
\text { ment: ( } 1 \text { ) when } n \neq 0 \text {, use of the inverse axiom must be made and thus multi- } \\
\text { plication by } n^{-1} \text { and (2) when } n=0 \text {, it must be deduced that } m=0 \text { and therefore } \\
|m|=|n| \text {. }\end{array}$ \\
\hline $\begin{array}{l}\text { TASK } 3 \\
\text { Argument 3: improper use } \\
\text { of the definitions of odd } \\
\text { and even integer }\end{array}$ & $\begin{array}{l}\text { Manifests that the argument is not a proof because the definitions of odd and } \\
\text { even number are used incorrectly. } \\
\text { Manifests that the definition of odd number should be employed for correcting } \\
\text { the argument to express that } 2 p+1=m \text { and } 2 q+1=n \text {; and the definition of } \\
\text { even number to conclude that } m+n=2 j \text { with } j \in \mathbb{Z} \text {. }\end{array}$ \\
\hline $\begin{array}{l}\text { TASK } 4 \\
\text { Argument 4: proper } \\
\text { mathematical proof of the } \\
\text { theorem of the sum of the } \\
\text { measures of the interior } \\
\text { angles of a triangle in }\end{array}$ & $\begin{array}{l}\text { Manifests that the hypothesis of the theorem considers any triangle in Euclid- } \\
\text { ean geometry. } \\
\text { Manifests that the parallel postulate of Euclidean geometry is employed in the } \\
\text { argument. } \\
\text { Manifests that mathematical definitions are employed in the argument. } \\
\text { Manifests that mathematical theorems are employed in the argument. }\end{array}$ \\
\hline
\end{tabular}

Note: Own source from the present investigation. 
For each subject, an exhaustive review of their responses was carried out in a similar manner as was done for questionnaire 1 . In this way, the presence or absence of the defined knowledge indicators were assigned as $\mathbf{1}$ or $\mathbf{0}$, respectively. Additionally, the responses, and a synthesis of them, that could not be classified by such indicators were recorded.

\section{Results}

This section presents the results on the knowledge of mathematics teachers in initial training (MTITs) relative to the evaluation of mathematical arguments. In the first section, the logic-syntactic aspects are considered followed by mathematical aspects.

\section{Results of empirical phase 1: spe- cialized knowledge about the logic validity of the mathematical proof}

The results are presented considering the four categories generated when evaluating mathematical arguments to prove proposition $P$ : any real number satisfies that, if it is positive, then the sum of it and its multiplicative inverse is greater than or equal to two: (1) proof by a particular case, (2) proof of reciprocal, (3) direct proof of the universal implication and (4) proof of the universal implication by reduction to absurdity. For each argument, it is presented the number of subjects who considered the argument to be a proof and who evidenced knowledge of the proposed indicators in their responses. In addition, and when appropriate for each argument, it is presented the synthesis of the responses that could not be classified by the defined indicators and that evidenced knowledge of the logic-syntactic aspects of the proof.

\section{Argument 1: Proof by a particular case}

In the evaluation of this argument, 23 of the 25 subjects considered the argument did not to correspond to a mathematical proof of the given proposition and all of the subjects were aware that this was due to the fact that the argument only considered a particular case. A representative response follows:

As it is a proposition that applies to all the elements of the set $(\mathbb{R})$, it is not possible to demonstrate it by means of a specific example with one particular element, instead, one must initiate by considering a generic element from the set, the generic element being representable of any element of that set, and prove with it that the property is satisfied (SBM10).

A group of six subjects considered that the argument would be a mathematical proof if the proposition had an existential quantifier, which evidences knowledge about how to prove a proposition with said quantifier by exhibiting a concrete element of the universe. A representative response follows:

The number $(2-\sqrt{3})$ is specifically taken, however the proposition applies for all numbers, thus the argument is valid to demonstrate that there is a number that does satisfy the proposition (SBW05).

\section{Argument 2: Proof of reciprocal}

In the evaluation of this argument, 23 of the 25 subjects considered that it did not correspond to a mathematical proof of the given proposition and 19 subjects evidenced knowledge that this was due to the fact that the argument considered the reciprocal of 
the predicate. Some representative responses are as follows:

$>$ Because the proposition has an implication form $(P \Rightarrow Q)$, one must assume the antecedent to be true and seek to prove the consequent, not vice versa, since this would not be the logic structure (SBM16).

$>$ Because the proposition $P$ is $\forall x \in \mathbb{R}((x$ $\left.>0) \Rightarrow\left(x+x^{-1} \geq 2\right)\right)$ (expressed symbolically) and in the given argument, the reciprocal is proved, that is, $\forall x \in \mathbb{R}((x$ $\left.\left.\left.+x^{-1} \geq 2\right)\right) \Rightarrow(x>0)\right)($ SLW07).

\section{Argument 3: Direct proof of the universal implication}

In the evaluation of this argument, 22 of the 25 subjects considered that it corresponded to a mathematical proof of the given proposition and all subjects manifested to possess knowledge. Table 5 presents the number of subjects whose responses displayed evidence of the knowledge indicators defined for the direct proof of the universal implication.

As can be seen in the previous table, most of the subjects evidence knowledge about how to proceed in the direct proof of the universal implication, that is, they know that the antecedent must be assumed to be true and, subsequently, the veracity of the consequent must be guaranteed. Nonetheless, very few subjects made explicit reference to the selection of an arbitrary element of the universe set, which is precisely what supports the way of proceeding in directly proving the implication. Likewise, none of the subjects expressed the validity of the property for all the elements of the universe set by virtue of the fact that it was guaranteed for a generic element. Some representative responses include:

Because the proposition has an implication form, it is assumed that $x>0$ is true and it must be verified that the sum of the number and its multiplicative inverse is true, as shown in the box. Besides, verification is performed for an arbitrary but fixed value of $x$ (SBM16).

$>$ It starts correctly, according to the given quantifier, by providing any element that is real. Then, implication is correctly used with the hypothesis that $x>0$ and mention is made of the consequent (what needs to be proved). The consequent is then proved from the operation $x+\frac{1}{x}-2$, which is utilized out of convenience, whilst already knowing that

Table 5. Number of subjects evidencing knowledge indicators for the direct proof of the universal implication.

\begin{tabular}{lc}
\hline \multicolumn{1}{c}{ Knowledge indicators } & Task 3 \\
\hline Manifests that an arbitrary element of the universe $\mathbb{R}$ must be considered. & 8 \\
Manifests that the antecedent $x>0$ must be assumed to be a true proposition. & 20 \\
Manifests that it must be guaranteed that the consequent $\left(x+\frac{1}{x}\right) \geq 2$ is a true proposi- & 20 \\
tion based on the antecedent $x>0$ and the mathematical theory where both proposi- \\
tions are inserted. \\
Manifests that the property $x>0 \Rightarrow\left(x+\frac{1}{x}\right) \geq 2$ is satisfied for all the elements of the \\
universe set $\mathbb{R}$ because it had been validated for an arbitrary element.
\end{tabular}

Note: Own source from the present investigation. 
its equivalent expression is greater than or equal to zero, thus the expression is also greater than or equal to zero and manages to prove the consequent of the implication (SLM02).

\section{Argument 4: Proof of the univer- sal implication by reduction to absurdity}

In the evaluation of this argument, 21 of the 25 subjects considered that it corresponded to a mathematical proof of the given proposition and 16 of them manifested knowledge of the three proposed indicators. In addition, four subjects affirmed that the argument was a proof, although their responses did not evidence any indicator as was the case for the four subjects who declared that it was not a mathematical proof.

Table 6 presents the number of subjects whose responses displayed evidence of the knowledge indicators defined for the proof of the universal implication by reduction to absurdity.

Some representative responses of the subjects who evidenced knowledge include:

$>$ Indeed it corresponds to a for all $(\forall)$ proof or for any positive real number proof, because it emanates from the assumption that there must exist an element that does not fulfill the proposition and when reaching a contradiction, there is nothing left but to conclude that the proposition is true (SBM17).

$>$ It stems from the assumption that the proposition $P$ is false and a logic contradiction is being reached, this concludes that the proposition $P$ cannot be false and according to the Law of excluded middle the proposition must be true, thus constituting a proof of proposition $P$ (SLM06).

Based on the results presented in this section, it can be seen that a large majority of future mathematics teachers possess knowledge to discriminate whether or not an argument is a mathematical proof of an arithmetic property such as the one proposed. Their knowledge allows them to recognize perverse justifications that cannot be considered proofs, such as the proof by a particular case, or that of the reciprocal theorem; their insight also allows them to recognize when the precise steps have been followed to prove the proposition. Nonetheless, the number of subjects who identify the

Table 6. Number of subjects evidencing knowledge indicators for the proof of the universal implication by reduction to absurdity

\begin{tabular}{lc}
\hline \multicolumn{1}{c}{ Knowledge indicators } & Task $\mathbf{3}$ \\
\hline Manifests that the negation of the given proposition must be assumed to be true and & 16 \\
that it is equivalent to the proposition $\exists x \in \mathbb{R}\left[x>0 \wedge\left(\frac{x^{2}+1}{x}\right)<2\right]$. & 16 \\
Manifests that it must be demonstrated that $\neg \forall x \in \mathbb{R}\left(x>0 \Rightarrow\left(x+\frac{1}{x}\right) \geq 2\right) \Rightarrow F_{0}$ where \\
$F_{0}$ represents any contradictory statement, in this case $F_{0}$ is the contradiction $\left((x-1)^{2}\right.$ \\
$\left.<0 \wedge(x-1)^{2} \geq 0\right)$. \\
Manifests that once $F_{0}$ is guaranteed then $\neg \forall x \in \mathbb{R}\left(x>0 \Rightarrow\left(x+\frac{1}{x}\right) \geq 2\right)$ must be false \\
and, consequently, $\forall \boldsymbol{x} \in \mathbb{R}\left(\boldsymbol{x}>\mathbf{0} \Rightarrow\left(\boldsymbol{x}+\frac{1}{x}\right) \geq \mathbf{2}\right)$ must be true.
\end{tabular}

Note: Own source from the present investigation. 
steps when a reduction to absurdity proof is proposed decreases considerably.

\section{Results of empirical phase 2: Spe- cialized knowledge on the mathe- matical validity of the proof}

The results are presented considering the four categories defined in this second phase to analyze the responses provided by research subjects regarding their indication of whether the argument corresponded to a mathematical proof of the given proposition, explaining the reasons for their choice and, in the case that the provided argument was not deemed a mathematical proof, indicate the modifications they would realize to the mathematical argument to make it a mathematical proof. For each category is presented the number of subjects who considered the proposed argument to be a proof and whose responses evidenced knowledge of the proposed indicators. In addition, and when appropriate, it is presented the synthesis of the responses that were not contemplated by the indicators and that evidence knowledge of the mathematical aspects of proving.

Category 1: Partial use of the
non-negative
hypothesis

In the evaluation of this argument in task 1,17 of the 19 subjects considered that it did not correspond to a mathematical proof of the given proposition and 15 subjects displayed evidenced of at least one of the defined knowledge indicators. Additionally, two subjects manifested that the argument was a proof, but did not evidence any indicator as did two other subjects who manifested that it was not a mathematical proof. Table 7 presents the number of subjects whose responses displayed evidence of the knowledge indicators defined for this category.

Representative responses provided by two subjects are presented. Both manifested that the argument was not a proof due to the partial use of the hypothesis, subject SLM06 completes his assessment by exhibiting a real number to satisfy existence, while subject SBW12 does not:

Explanation: It is only shown that the mathematical proposition is valid for the case when $b^{2}-4 a c=0$, it would be necessary to prove it for the case when $b^{2}-4 a c=0$. It uses a particular case. Correction: For the case when $b^{2}-4 a c$ $=0$. It suffices to consider the real number $x=\frac{-b+\sqrt{b^{2}-4 a c}}{2 a}$. Then

Table 7. Number of subjects evidencing category 1 knowledge indicators: Partial use of the non-negative discriminant hypothesis.

\begin{tabular}{lc}
\hline \multicolumn{1}{c}{ Knowledge indicators } & Task 1 \\
\hline $\begin{array}{l}\text { Manifests that the argument is not a proof because the hypothesis }\left(b^{2}-4 a c\right) \geq 0 \text { is } \\
\text { partially used. }\end{array}$ & 15 \\
Manifests that the hypothesis $\left(b^{2}-4 a c\right) \geq 0$ must be considered for correcting the argu- \\
ment, however, it does not exhibit any of the real numbers that satisfy existence. \\
Manifests that the hypothesis $\left(b^{2}-4 a c\right) \geq 0$ must be considered in order to exhibit any \\
of the real numbers $x=\frac{-b+\sqrt{b^{2}-4 a c}}{2 a}$ or $x=\frac{-b-\sqrt{b^{2}-4 a c}}{2 a}$ for correcting the argument.
\end{tabular}

Note: Own source from the present investigation. 


$$
\begin{gathered}
a x^{2}+b x+c=a\left(\frac{-b+\sqrt{b^{2}-4 a c}}{2 a}\right)^{2}+b\left(\frac{-b+\sqrt{b^{2}-4 a c}}{2 a}\right)+c \\
=\frac{d}{4 d^{2}}\left(b^{2}-4 a c-2 b \sqrt{b^{2}-4 a c}+b^{2}\right)+\frac{b \sqrt{b^{2}-4 a c}-b^{2}}{2 a}+c \\
=\frac{b^{2}-4 a c-2 b \sqrt{b^{2}-4 a c}+b^{2}}{4 a}+\frac{b \sqrt{b^{2}-4 a c}-b^{2}}{2 a}+c \\
=\frac{2 b^{2}-4 a c-2 b \sqrt{b^{2}-4 a c}}{4 a}+\frac{b \sqrt{b^{2}-4 a c}-b^{2}}{2 a}+c \\
=\frac{2\left(b^{2}-2 a c-b \sqrt{b^{2}-4 a c}\right)}{4 a}+\frac{b \sqrt{b^{2}-4 a c}-b^{2}}{2 a}+c \\
=\frac{b^{2}-2 a c-b \sqrt{b^{2}-4 a c}+b \sqrt{b^{2}-4 a c}-b^{2}+2 a c}{2 a} \\
=\frac{0}{2 a} \\
=0
\end{gathered}
$$

Thus, the real number $x=\frac{-b+\sqrt{b^{2}-4 a c}}{2 a}$ satisfies existence (SLM06).

$>$ Explanation: In the hypothesis it is stated that $b^{2}-4 a c \geq 0$, but when the proof is performed, only the case where $b^{2}-4 a c$ $=0$ is taken into account without considering the case for greater than zero, thus, the proof is not entirely correct. Correction: I would consider both cases, $b^{2}-$ $4 a c=0$ and $b^{2}-4 a c>$. Therefore, it will be necessary to search for an $x \in \mathbb{R}$ that fulfills the second case (SBW12).

\section{Category 2: Improper use of the ax- iom of existence of the multiplica- tive inverse}

In this argument, present in task 2, only seven subjects appreciated the abusive quality of the reasoning, manifesting that it was not a mathematical proof and, of them, five evidenced the reason by means of one of the proposed indicators. Table 8 presents the number of subjects whose responses displayed evidence of the knowledge indicators defined for this category.

As can be seen in the previous table, five subjects manifested that the argument was not a proof due to the improper use of the multiplicative inverse axiom and, of them, four evidenced in their argument corrections of the need to consider two cases: when $n \neq 0$ and $n=0$. Presented are representative responses of two subjects who manifested that the argument was not a proof due to the improper use of the multiplicative inverse axiom, one belongs to subject SBM02 whose correction argument makes reference to the consideration of cases to utilize the multiplicative inverse while the response of subject SBM03 does not:

Explanation: Because it is generalized for any $m, n \in \mathbb{Z}$ and initiates from the fact that $m$ divides $n$ and $n$ divides $m$, although if one of them is zero for them to be divisible with each other, both must be zero. To avoid $n^{-1}$ which is undefined in the case when it is zero. Correction: Considering $n, m \in \mathbb{Z}-\{0\}$ Case I as was done. Separately Case II for $n=0$ and $m / n \Rightarrow m / 0 \Rightarrow m q=0, q \in \mathbb{Z}$ and since $n / m \Rightarrow n k=m, k \in \mathbb{Z} \Rightarrow 0 k=m \Rightarrow$ $m=0$. Therefore $|0|=|0|$. Thus by case I and case II $|m|=|n|$ (SBM02).

Table 8. Number of subjects evidencing category 2 knowledge indicators: improper use of the axiom of existence of the multiplicative inverse

\begin{tabular}{lc}
\hline \multicolumn{1}{c}{ Knowledge indicators } & Task 2 \\
\hline Manifests that the argument is not a proof because the multiplicative inverse axiom is & 5 \\
used incorrectly when considering the real number $n^{-1}$ without guaranteeing that $n \neq 0$. & 4 \\
Manifests that two cases must be considered for the correction of the argument: $(1)$ & \\
when $n \neq 0$, use of the inverse axiom must be made and thus multiplication by $n^{-1}$ and & \\
(2) when $n=0$, it should be deduced that $m=0$ and therefore $|m|=|n|$. &
\end{tabular}

Note: Own source from the present investigation. 
$>$ Explanation: The proof is incomplete, the definition that one number is divisible by another is used correctly, and all the rest of the steps are correct. However, it seems adequate to include the case $n=0$ o $m=0$, because in one step we are multiplying both sides of the inequality by $n^{-1}$, but it is clear that $n$ will not be equal to 0 , or else the hypothesis that $\mathrm{m} / \mathrm{n}$ and $n / m$ would be contradicted, as we end up with $m / 0$ and $0 \times m$. The same would occur if $m=0$. For 0 to be satisfied, both $m, n$ must be 0 . Corrección: If $m$ $=0, n \neq 0, n / 0$ y $0 \times{ }_{n}$ ! contradicts the hypothesis. If $n=0, m \neq 0, m / 0$ y $0 X$ $m i$ ! contradicts the hypothesis. If $n=$ $0, m \neq 0, m / 0$ y $0 \times m i !$, the theorem holds since $|0|=|0|$ (SBM03).

Regarding the 12 subjects who manifested that the argument was a mathematical proof, none of them evidenced any of the proposed indicators. However, three of them made reference to the multiplicative inverse in their explanation. Subject SBW11 stated that it was unnecessary for $n^{-1}$ to be an integer, but without specifying that its existence would not be guaranteed in the event that $n$ was zero. Subjects SBW05 and SBM16 manifested that $n^{-1}$ exists when $n$ is different from zero, however, they evidenced knowledge on the concept of divisibility that implied that $n$ was different from zero. Following, the three responses:

$>$ Explanation: $n^{-1}$ does not need to be an integer, so it would not affect us at any time. In addition, it is initiated from the definition to conclude with a truth value (SBW11).
$>$ Explanation: The arguments are correct. It is clear that if $m / n$ and $n / m, n$ and $m$ cannot be zero. It would then be appropriate to specify that $n^{-1}$ exists. Hypotheses are separated, translation is performed correctly, and properties are adequately applied. Clearly draws a conclusion in which it is evidenced what needed to be proved (SBW05).

$>$ Explanation: The only problem that the argument could present is when it is multiplied by $n^{-1}$ in the equality, however, due to the hypothesis $m / n$; then $m \neq 0$ and since $n / m$ then $n \neq 0$, thus $n^{-1}$ is perfectly defined. Because of this, all reasonings thereafter, make perfect sense, and also all the gaps that could remain are covered, the only thing that can be added is that the substitution can be carried out in any of the two equations resulting from the definition of $m / n$ and $n / m$ (SBM16).

The previous answers demonstrate that subjects SBW05 and SBM16 considered the argument as a proof due to inaccuracies in their knowledge about divisibility, however, they evidence knowledge that a real number has a multiplicative inverse if it is different from zero.

\section{Category 3: Improper use of the definitions of odd and even integer}

In this argument, present in task 3, 16 of the 19 subjects manifested that it was not a mathematical proof and, of them, 14 evidenced some of the proposed indicators. In addition, three subjects stated that the argument was a proof, but did not evidenced any indicator, as did two other subjects who manifested that it was not a mathematical proof. Table 9 presents the number of 
Table 9. Number of subjects evidencing category 3 knowledge indicators: improper use of the definitions of odd and even integer

\begin{tabular}{lc}
\hline \multicolumn{1}{c}{ Knowledge indicators } & Task 2 \\
\hline $\begin{array}{l}\text { Manifests that the argument is not a proof because the definitions of odd and even } \\
\text { numbers are used incorrectly. }\end{array}$ & 13 \\
Manifests that the definition of odd number should be employed for correcting the & 14 \\
argument to express that $2 p+1=m$ and $2 q+1=n$; and the definition of even number \\
to conclude that $m+n=2 j$ with $j \in \mathbb{Z}$
\end{tabular}

Note: Own source from the present investigation.

subjects whose responses displayed evidence of the knowledge indicators defined for this category.

As can be seen in the table above, 13 subjects manifested that the argument was not a demonstration due to the improper use of the definitions of even and odd integer and all of them evidenced the correct use of the definitions in the correction of the argument. There was a subject, SBM02, who did not evidenced the first indicator in his explanation, however, in the correction of the argument, he manifested knowledge of the second indicator.

Representative responses from three subjects who manifested that the argument was not a proof are presented. Following, the response of the SBM02 subject mentioned in the previous paragraph and the responses of SBW12 and SLM02 who evidenced knowledge of the two raised indicators:

$>$ Explanation: $2 m+1=p$ is considered in line 3 , clearly $p$ is taken as an even number. Thus $2 m+1=p \Rightarrow 2 m=p-$ $1 \Rightarrow m=\frac{p-1}{2}$ and $p$ is even, then $p-1$ is odd, so $m=\frac{p-1}{2} \notin \mathbb{Z}$ since $2 X(p-1)$. The same rationale applies for $2 n+1=$ $q$. Correction: Consider $m=2 p+1$ and $n=2 q+1$ in line 3. Then, $m+n=2 p+$ $1+2 q+1=2 p+2 q+2=2(p+q+2)$. Where $p+q+2 \in \mathbb{Z}$. Take $a=p+q+2$. Thus, $m+n=2(p+q+2)=2 a$ which is the definition of an even integer. Guaranteeing that $m+n$ is even (SBM02).

$>$ Explanation: By stating that $2 m+1=$ $p$, it is guaranteed that $p$ is odd, however, it does not guarantee that $m$ is odd, since if $m$ is even or odd the same is true. On the other hand, it is arrived at $2(m+n)=j, j \in \mathbb{Z}$ guarantees that $j$, but not $m+n$, is even, the latter sum could be odd but when it is multiplied by $2, j$ becomes an even number. Correction: It is best to take the definitions for $m$ and $n$, as $m=2 p+1$ y $n=2 q+$, so that when they are added the result is $m+n=2(p$ $+q+1)$ thereby ensuring that $m+n$ is even (SBW12).

Explanation: The values of $m$ and $n$ are defined incorrectly as integers, also they should be inverted, that is, the value of $m$ should be flipped for $p$, and likewise $n$ for $q$. Correction: Since $m$ and $n$ are odd, they satisfy that: $m=2 p+1$ and $n$ $=2 q+1$, with $p, q \in \mathbb{Z}$. Then $m+n=2 p$ $+2 q+2 \Rightarrow m+n=2(p+q+1)$, with $p, q \in \mathbb{Z}$. Thus, $m+n=2 \cdot r$, with $r=p$ $+q+1$ and $r \in \mathbb{Z}$ having the form of an even number $m+n$ (SLM02). 
Category 4: Proper use of hypotheses, axioms, definitions and theorems in the proof of the theorem of the sum of the measures of the interior angles of a triangle in Euclidean geometry

In this argument, present in task 4, all 19 subjects stated that it was a mathematical proof, however, most subjects limited themselves to a mere statement since only nine subjects showed any of the proposed knowledge indicators. Table 10 presents the number of subjects whose responses displayed evidence of the defined knowledge indicators for this category.

Based on the previous table, it can be noted that, despite the fact that all future mathematics teachers identified as valid the proof of the property of the sum of the measures of the interior angles of a triangle, none made reference to the fact that the proposition is a general statement, which stems from the hypothesis that any triangle in Euclidean geometry was to be considered. However, two subjects evidenced knowledge about the use of the parallel postulate, definitions and theorems, simultaneously; four subjects only evidenced the use of the parallel postulate; and three subjects only evidenced the use of mathematical theorems in the argument. To illustrate this, three responses are presented: that of subject SBW12 evidences the use of the parallel postulate, definitions and theorems; that of subject SBM02 refers only to the parallel postulate; and that of the subject SBW05 refers only to the use of theorems:

$>$ Explanation: The theorems being used have already been proven, namely, the parallel postulate and the alternate interior angles postulate between parallels. Similarly, definitions such as linear pair and interior angle are properly employed (SBW12).

$>$ Explanation: Euclidean geometry is guaranteed to be established. Thus Euclid's $5^{\text {to }}$ postulate (parallel postulate) is true. In addition, it guarantees that the generated points create a linear pair to correctly substitute the angles for their corresponding internal alternates. This demonstrates that the sum of interior angles is $180^{\circ}$ (SBM02).

$>$ Explanation: All statements and theorems are used correctly. Clearly shows that each of the steps is true. Uses properties. Starts from hypotheses, applies the properties correctly, and clearly indicates what needs to proved. Realizes the conclusion (SBW05).

Table 10. Number of subjects evidencing category 4 knowledge indicators: proper use of hypotheses, axioms, definitions and theorems in the proof of the theorem of the sum of the measures of the interior angles of a triangle in Euclidean geometry

\begin{tabular}{lc}
\hline \multicolumn{1}{c}{ Knowledge indicators } & Tasks 2 \\
\hline $\begin{array}{l}\text { Manifests that the hypothesis of the theorem is to consider any triangle in Euclidean } \\
\text { geometry. }\end{array}$ & 0 \\
Manifests that the parallel postulate of Euclidean geometry is employed in the argu- & 6 \\
ment. & 2 \\
Manifests that mathematical definitions are employed in the argument. & 5 \\
Manifests that mathematical theorems are employed in the argument.
\end{tabular}
Note: Own source from the present investigation. 
For the 10 research subjects who indicated that the argument was a proof of the given proposition, but who did not evidence any of the proposed indicators, in their answers we found inaccuracies to justify the validity of a correct mathematical argument, basing their answers on generalities such as: the presence of an adequate logic structure, that is, starting from a true proposition and generating true partial conclusions that lead to the conclusion, the consideration of all the possibilities and their corresponding justification, the use of previous results from Euclidean geometry and the clarity of the argument.

Based on the results presented in this section, it can be seen that all future mathematics teachers evidence knowledge to determine when an argument constitutes a mathematical proof of a proposition, although few subjects provide the justifications for it. Likewise, the vast majority evidence knowledge to discriminate if an argument does not correspond to a mathematical proof based on mathematical aspects such as the partial use of the hypothesis and the improper use of definitions. However, there is a significant decrease in subjects that identify the improper use of the multiplicative inverse axiom.

Regarding the correction of the arguments that do not correspond to a mathematical proof, there is a decrease in the number of subjects who consider in their proposals to modify the argument, the mathematical aspects that invalidated it: (1) in argument 3,14 of 19 subjects suggested that the definitions of odd and even number should be modified, (2) in argument 1,7 of 19 subjects indicated that the complete hypothesis of the non-negative discriminant should be used and exhibited some real number to satisfy existence, while 8 of 19 subjects only made reference to the use of the complete hypothesis and (3) in argument 2, 4 of 19 subjects manifested that two cases must be considered for the number in question, when it was zero and when it was different from zero to be able to use the multiplicative inverse axiom.

\section{Conclusions}

Most of the mathematics teachers in initial training (MTITs) evidenced knowledge of the logic-syntactic aspects in the evaluation of the four mathematical arguments proposed in questionnaire 1 for universal implication, corresponding to the mathematical proposition $P$ : any real number satisfies that, if it is positive, then the sum of it and its multiplicative inverse is greater than or equal to two.

For the first two arguments, the majority of the subjects manifested that they did not correspond to a proof, appreciating that, in the first argument, the proof alluded to a particular case and that in the second, the reciprocal of the predicate was proved. For the third and fourth arguments, the majority of subjects indicated that they did correspond to proofs. In the case of the third argument, regarding the direct proof of the universal implication, the majority of subjects evidenced knowledge that the antecedent had to be assumed to be true and subsequently, guarantee the veracity of the consequent. However, only a minority evidenced knowledge about the consideration of a generic element of the universe and none made reference to the fact that the property was valid by virtue that it had been guaranteed for a generic element that represents any element of the universe. These results coincide with those obtained by $\mathrm{Du}-$ rand-Guerrier et al. (2012b). In the fourth 
argument, regarding the proof by reduction to absurdity of the universal implication, the majority of subjects displayed evidence of knowledge of the three proposed indicators, namely, that the negation of the given proposition should be assumed, that a contradiction should be generated and once generated, it could be concluded that the original proposition was true.

The proposition of questionnaire 2 was used by Knuth (2002) in his research with 16 mathematics teachers where he presented them with an argument that proved the reciprocal predicate. According to this researcher, 10 teachers considered it as a proof and focused on correcting the algebraic manipulations more than on validity aspects. In our study, the majority of mathematics teachers in initial training (MTITs) focused on logic correction rather than on the mathematics employed in each argument, which allows us to observe adequate knowledge of the logic-syntactic aspects involved in proving by universal implication. Specifically, MTITs evidence knowledge to discern that the consideration of a particular case does not constitute mathematical proving, and they appreciate the argument that uses this fallacy. Also, they have demonstrated to possess knowledge on how to proceed in direct and reduction to absurdity proving.

The study of knowledge regarding the mathematical aspects of proving is complex, since, in addition to logic-syntactic elements, concepts and their meanings intervene in the mathematical theory in which proofs are inserted. In this sense, Mariotti (2006) points out that, contrary to what happens within a formal theory, in the practice of mathematical deduction there exists dependence on the comprehension and prior assimilation of the meaning of the concepts from which certain properties are followed logically. The mathematical aspects considered in this investigation such as hypotheses, axioms, definitions and theorems could have presented different levels of difficulty in understanding a proof.

In the case of the first argument, corresponding to the category denominated "partial use of the non-negative discriminant hypothesis" (in a second degree equation in a real variable), the hypothesis appears explicitly in the proposition to be proved. The vast majority of the research subjects evidenced that it was not a proof due to this partial use. In correcting the argument, a minority of the subjects evidenced knowledge regarding the fact that the hypothesis of the discriminant must be considered in its entirety and also sought and proposed a real number that would comply with existence.

In the remaining three arguments, the definitions, axioms and theorems employed are not necessarily explicit in the proposition to be proved and, therefore, the subjects are required to know them in depth in order to evaluate their use during proving. In the second argument corresponding to the category denominated "improper use of the axiom of existence of the multiplicative inverse" (to demonstrate the equality in absolute value of two integers divisible by each other), very few subjects evidenced knowledge about the argument not being a proof due to the improper use of the multiplicative inverse. Likewise, very few subjects, in their suggested argument correction, manifested that the number in question must be considered to be non-zero in order to use its multiplicative inverse.

In the third argument corresponding to the category denominated "improper use of the definitions of even and odd integers" (to demonstrate the parity of the sum of two odd numbers), the majority of subjects 
evidenced that it was not a proof due to the inappropriate use of definitions. In correcting the argument, most subjects evidenced knowledge of the algebraic conditions that characterize odd and even numbers, possibly because they have used them frequently in undergraduate courses. However, the ignorance of all the conditions of the definitions could lead to the subjects misjudging an argument. For example, in the second argument, two subjects considered that in the definition of divisibility the numbers involved are necessarily non-zero, therefore, existence of the multiplicative inverse was justified for them, which implied that they considered the argument to be a proof.

In the fourth argument corresponding to the category denominated "proper use of hypotheses, axioms, definitions and theorems in the proof of the theorem of the sum of the measures of the interior angles of a triangle in Euclidean geometry", the totality of the subjects manifested that the argument was a mathematical proof. However, only a minority evidenced knowledge of the proposed indicators. This fact suggests that it is easier to explain when a mathematical argument has errors than to justify its correctness.

According to Mariotti (2006), traditionally, the mathematical proof is considered in itself possible of being separated from the proposition which it supports and from the theoretical framework within which such support makes sense. In the present research it has been evidenced that the vast majority of research subjects (MTITs) took notice that in a proof all these elements are involved simultaneously and it is impossible to comprehend the meaning of a mathematical proof without linking the proposition to which it refers and the mathematical theory in which it is inscribed. In this way, in mathematical practice the truth values of propositions are proved, but the term "truth" must always be understood in relation to a particular theory.

The results obtained support the appreciation of Cabassut et al. (2012) in which they affirm that the mathematical proof does not establish facts, but rather guarantees the validity of propositions of the type "if-then", this implies that the hypotheses, axioms, theorems and definitions must be understood and applied in their precise meanings within a mathematical theory. It is thus considered that the mathematical aspects of proving can contribute to the specialized knowledge of mathematics teachers to understand that mathematical results are not universal truths. For example, when it is stated that the sum of the measures of the interior angles of any triangle is 180 degrees, the knowledge about the mathematical validity of the proof allows us to understand that in a certain theory this result can be derived.

\section{Acknowledgements}

This work is part of the Project «Conocimiento Didáctico del Profesor y Aprendizaje de Conceptos Matemáticos Escolares» (EDU2015-70565-P) (translated as "Teacher didactic knowledge and learning of school mathematical concepts" of the $\mathrm{Na}$ tional Plan for R+D+I (MICIN) and the Andalusian Plan for Research, Development and Innovation (Group FQM-193, Didactics of Mathematics. Numerical Thinking). In addition, it had the support of project PCG2018-095765-B-I00 of the National Plan for R+D+I (MICIN) and the Andalusian Plan for Research, Development and Innovation (Group FQM-193, Didactics of Mathematics. Numerical Thinking) and the 
School of Mathematics of the Universidad Nacional in Costa Rica.

\section{Informed consent}

The authors declare that the participants (subjects) of this study were informed about the treatment of the information.

\section{Conflict of interests}

The authors declare that they have no conflict of interest.

\section{Authors' declaration of contribution}

The total percentage of contribution for the conceptualization, preparation and correction of this article was the following: C.A.C. $50 \%$, P.F.M. $25 \%$ and G.V.S. $25 \%$.

\section{Declaration of data availability}

The data supporting the results of this study will be made available by the corresponding author [C.A.C.], upon reasonable request.

\section{Referencias}

Alfaro, C.; Flores, P. \& Valverde, G. (2019). La demostración matemática: Significado, tipos, funciones atribuidas y relevancia en el conocimiento profesional de los profesores de matemáticas. Uniciencia, 33(2), 55-75. https://doi.org/10.15359/ru.33-2.5

Ayalon, M. \& Even, R. (2008). Deductive reasoning: In the eye of the beholder. Educational Studies in Mathematics, 69(3), 235-247. https:// doi.org/10.1007/s10649-008-9136-2

Bryman, A. (2012). Social research methods. Oxford University Press.

Buchbinder, O. \& McCrone, S. (2018). Taking proof into secondary classrooms-supporting future mathematics teachers. In T.E. Hodges, G. J. Roy, \& A. M. Tyminski (Eds.), Proceedings of the 40th annual meeting of the North American Chapter of the International Group for the Psychology of Mathematics Education. University of South Carolina \& Clemson University.

Cabassut, R., Conner, A., İşçimen, F. A, Furinghetti, F., Jahnke, H. N. \& Morselli, F. (2012). Conceptions of proof-In research and teaching. En G. Hanna y M. De Villiers (Eds.), Proof and proving in mathematics education (pp. 169-190). Dordrecht. https://doi. org/10.1007/978-94-007-2129-6 7

Carrillo, J., Climent, N., Montes, M., Contreras, L. C., Flores-Medrano, E., Escudero-Ávila, D. \& Muñoz-Catalán, C. (2018). The mathematics teacher's specialised knowledge (MTSK) model. Research in Mathematics Education, 20(3), 236-253. https://doi.org/10.1080/1479 4802.2018.1479981

Cohen, L., Manion, L. \& Morrison, K. (2007). Research Methods in Education. Routledge. https://doi.org/10.4324/9780203029053

Crespo, C. \& Ponteville, C. (2005). Las funciones de la demostración en el aula de matemática. Acta Latinoamericana de Matemática Educativa, 18, 307-312. http://funes. uniandes.edu.co/5954/1/CrespoFuncionesAlme2005.pdf

Durand-Guerrier, V., Boero, P., Douek, N., Epp, S. S. \& Tanguay, D. (2012a). Argumentation and proof in the mathematics classroom. En G. Hanna y M. De Villiers (Eds.), Proof and proving in mathematics education (pp. 349-367). Springer. https://doi. org/10.1007/978-94-007-2129-6_15

Durand-Guerrier, V., Boero, P.; Douek, N., Epp, S. S. $\&$ Tanguay, D. (2012b). Examining the role of logic in teaching proof. En G. Hanna y M. De Villiers(Eds.), Proof and proving in mathematics education (pp. 369-389). Springer. https:// doi.org/10.1007/978-94-007-2129-6 16

Elbaz, F. (1983). Teacher Thinking. A Study of Practica! Knowledge. Croom Helm.

Flores, Á. (2007). Esquemas de argumentación en profesores de matemáticas del bachillerato. Educación Matemática, 19(1), 63-98.

Flores-Medrano, E., Montes, M., Carrillo, J., Contreras, L., Muñoz-Catalán, M. \& Liñán, M. (2016). El papel del MTSK como modelo de conocimiento del profesor en las 
interrelaciones entre los espacios de trabajo matemático. Bolema: Boletim de Educação Matemática, 30(54), 204-221. https://doi. org/10.1590/1980-4415v30n54a10

Garrido, M. (1991). Lógica simbólica. Editorial Tecnos.

Hanna, G. \& De Villiers, M. (2012). Aspects of proof in mathematics education. En G. Hanna y M. De Villiers (Eds.), Proof and proving in mathematics education (pp. 1-10). Springer. doi: https://doi. org/10.1007/978-94-007-2129-6_1

Knuth, E. J. (2002). Secondary school mathematics teachers' conceptions of proof. Journal for research in mathematics education, 33(5), 379-405. https://doi.org/10.2307/4149959

Krippendorff, K. (2004). Content analysis: An introduction to its methodology. Sage publications.

Lin, F. L., Yang, K. L., Lo, J. J., Tsamir, P., Tirosh, D. \& Stylianides, G. (2012). Teachers' professional learning of teaching proof and proving. En G. Hanna y M. De Villiers (Eds.), Proof and proving in mathematics education (pp. 327-346). Springer. https://doi. org/10.1007/978-94-007-2129-6_14

Lo, J. \& McCrory, R. (2009). Proof and proving in mathematics for prospective elementary teachers. En F.L. Lin, F.J. Hsieh, G. Hanna, \& M. de Villiers (Eds.), Proof and proving in mathematics education Vol. 2 (pp. 41-46). Springer.

Mariotti, M. A. (2006). Proof and proving in mathematics education. In A. Gutiérrez y P. Boero (Eds.), Handbook of research on the psychology of mathematics education (pp. 173-204).: Sense Publisher. https://doi. org/10.1163/9789087901127_008

Martínez-Recio, A. (1999). Una aproximación epistemológica a la enseñanza y aprendizaje de la demostración matemática [Tesis doctoral]. Universidad de Granada. Documento físico.

Ministerio de Educación Pública. (2012). Programas de estudio de matemáticas I, II y III ciclos de la educación general básica y ciclo diversificado. https://mep.go.cr/sites/default/files/ pro-gramadeestudio/programas/matematica. pdf

Montoro, V. (2007). Concepciones de estudiantes de profesorado acerca del aprendizaje de la demostración. Revista electrónica de investigación en educación en ciencias, 2(1), 101-121.
National Council of Teachers of Mathematics (NCTM). (2003). Principios y estándares para la educación matemática. SAEM Thales.

Patterson, C. (1950). Los principios del pensamiento correcto: lógica. Editorial Americalee.

Pietropaolo, R. \& Campos, T. (2009). Considerations about Proof in School Mathematics and in Teacher Development Programmes. En F.L. Lin, F.J. Hsieh, G. Hanna, \& M. de Villiers (Eds.), Proof and proving in mathematics education Vol. 2 (pp. 142-147). Springer.

Ponte, J. P. \& Chapman, O. (2006). Mathematics teachers' knowledge and practices. In A. Gutierrez \& P. Boero (Eds.), Handbook of reaserch on the psychology of mathematics education: Past, present and future (pp. 461-494). Sense Publisher. https://doi. org/10.1163/9789087901127_017

Ramos, M., Moreno, G. \& Marmolejo, E. (2015). Concepciones de profesores de bachillerato sobre la demostración matemática en contexto escolar. XIV Conferencia Interamericana de Educación Matemática, 14. http://xiv. ciaem-redumate.org/index.php/xiv_ciaem/ xiv_ciaem/paper/viewFile/1046/428

Roberts, C. (2010). Introduction to mathematical proofs: a transition.:Chapman y Hall/CRC. https://doi.org/10.1201/b17173

Rodríguez, J. (2003). Paradigmas, enfoques y métodos en la investigación educativa. Revista del Instituto de Investigaciones Educativas, 7(12), 23-40.

Sandín, M. (2003). Investigación cualitativa en educación: Fundamentos y tradiciones. McGraw-Hill.

Shulman, L. (1986). Those who understand: Knowledge ghrotw in teaching. Educational Researcher, 15(2), 4-14. https://doi. org/10.3102/0013189X015002004

Stylianides, A. J. (2007). Proof and proving in school mathematics. Journal for research in Mathematics Education, 38(3), 289-321.

Stylianides, G. J. \& Stylianides, A. J. (2009). Facilitating the transition from empirical arguments to proof. Journal for Research in Mathematics Education, 40, 314-352.

Stylianides, G. J., Stylianides, A. J. \& Weber, K. (2017). Research on the teaching and learning of proof: Taking stock and moving forward. In J. Cai (Ed.), Compendium for Research in Mathematics Education (pp. 237-266). 
Sullivan, P. \& Woods, T. (Eds.). (2008). The International Handbook of Mathematics Teacher Education. Sense Publisher.

Tabach, M., Levenson, E., Barkai, R., Tsamir, P., Tirosh, D. \& Dreyfus, T. (2009). Teachers' Knowledge of Students' Correct and Incorrect Proof Constructions. En F. L. Lin, F. J. Hsieh, G. Hanna, \& M. de Villiers (Eds.), Proof and proving in mathematics education Vol. 2 (pp. 214-219). Springer.

Tall, D., Yevdokimov, O., Koichu, B., Whiteley, W., Kondratieva, M. \& Cheng, Y. H. (2012). Cognitive development of proof. In Proof and proving in mathematics education (pp. 13-49). Dordrecht. https://doi. org/10.1007/978-94-007-2129-6_2

Vicario, V. \& Carrillo, J. (2005). Concepciones del profesor de secundaria sobre la demostración matemática: El caso de la irracionalidad de la raíz cuadrada de dos y las funciones de la demostración. En A. Maz, B. Gómez y M.
Torralbo (Eds.), Investigación en Educación Matemática. Noveno Simposio de la SEIEM (pp. 145-152). Universidad de Córdoba.

Viseu, F., Menezes, L., Fernandes, J. A., Gomes, A., \& Martins, P. M. (2017). Conceções de Professores do Ensino Básico sobre a Prova Matemática: influência da experiência profissional. Bolema, 31(57), 430-453. https://doi. org/10.1590/1980-4415v31n57a21

Winicki-Landman, G. (1998). On Proofs and Their Performance as Works of Art. The Mathematics Teacher, 91(8), 722-725. http://www.jstor. org/stable/27970759

Zaslavsky, O., Nickerson, S. D., Stylianides, A. J., Kidron, I. \& Winicki-Landman, G. (2012). The need for proof and proving: Mathematical and pedagogical perspectives. In Proof and proving in mathematics education (pp. 215-229). Dordrecht. https://doi. org/10.1007/978-94-007-2129-6_9

\section{(9) $10 \Theta \Theta$}

Knowledge of mathematics teachers in initial training regarding mathematical proofs: Logic-mathematical aspects in the evaluation of arguments (Christian Alfaro-Carvajal • Pablo Flores-Martínez • Gabriela-Valverde Soto) Uniciencia is protected by AttributionNonCommercial-NoDerivs 3.0 Unported (CC BY-NC-ND 3.0) 